\title{
Association of Carcinogenic Oral Habits with Oral Squamous Cell Carcinoma
}

\author{
Nazish Fatima ${ }^{1}$ \\ Sidra Mohiuddin ${ }^{2}$ \\ Salim Hosein ${ }^{3}$ \\ Mervyn Hosein ${ }^{4}$
}

\author{
BDS, MDS \\ BDS, MDS \\ MBBS, DABGS \\ BDS, FDS RCSE, FDS RCS, FFD RCSI
}

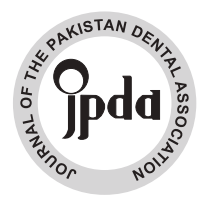

OBJECTIVE: To determine the association among betel nut, betel quid or smoking alone, and betel quid combined with smoking in subjects reporting with oral sub mucous fibrosis, oral submucous fibrosis with malignant transformation in to cancer and oral squamous cell carcinoma.

METHODOLOGY: An analytical cross sectional, multi centric study of $n=1009$ cases collected through non-probability convenience sampling. These $n=1009$ subjects were subdivided into four groups: group 1, who consumed areca nut only; group 2 , who chewed betel quid along with areca nut; group 3, who used betel quid and smoked; and group 4, who had no chewing habits history but were smokers. These changes were further confirmed with the help of biopsy reports of the subjects with OSMFCa and OSCC. Chi square test was performed to find out association of chewing habits with the progression of disease state. Level of significance was kept at $\mathrm{p} \leq 0.05$.

RESULTS: The mean age of the sample ( $\mathrm{n}=1009)$ were $42.79 \pm 1.31$ years (range: $10-70$ years). Statistically significant difference was $(p<0.00)$ found among all four groups in terms of initiation, propagation and progression of oral squamous cell carcinoma. Furthermore, statistically insignificant difference $(\mathrm{p}=0.40)$ was found between group 2 and group 3 as similar number of cases (OSCC) was seen among them.

CONCLUSION: Current study concluded that patients who have combined habits of chewing betel quid with areca nut and betel quid with smoking were at highest risk of initiation and progression of oral cancer. However, smoking cigarettes alone was the weakest risk factor.

KEYWORDS: Betel quid; Areca nut; Smoking; Oral squamous cell carcinoma, Oral submucous fibrosis

HOW TO CITE: Fatima N, Mohiuddin S, Hosein S, Hosein M. Association of carcinogenic oral habits with oral squamous cell carcinoma. J Pak Dent Assoc 2021;30(1):29-33.

DOI: https://doi.org/10.25301/JPDA.301.29

Received: 07 February 2020, Accepted: 09 September 2020

\section{INTRODUCTION}

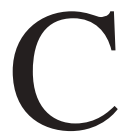
ancer is a global burden because of its high incidence and death rates. ${ }^{1,2}$ Amongst all cancers, oral cancer is the second most common cancer reported from developing countries. ${ }^{3,4}$ Evidence has shown that cancer is proven to be a disease of multifactorial origin, associated with varying risk factors among different population sub groups. ${ }^{5}$ However, factors that are primarily considered as established risk factors are: tobacco usage ; areca nut; heavy

1. Associate Professor, Department of Science of Dental Materials, Ziauddin College of Dentistry, Ziauddin University.

2. Associate Professor, Department of Community \& Preventive Dentistry, Ziauddin College of Dentistry, Ziauddin University.

3. Consultant Surgeon in Carbondale, Department of Fellow in Bariatric Surgery, Carbondale Illinois, USA.

4. Professor, Principal and Dean of Dental Sciences, Ziauddin College of Dentistry, Ziauddin University, Karachi.

Corresponding author: "Prof. Dr. Mervyn Hosein” < mmh5617@gmail.com > intake of alcohol; infection with human papillomavirus; and existence of oral potentially malignant disorders Since Pakistan is a developing country where people are suffering from oral cancer are mostly belong to low socioeconomic status. ${ }^{6}$ As this high risk group of the population; in addition to oral cancer is also suffering from nutritional deficiencies such as vitamin B12, folic acid and antioxidants therefore they get easily effected by the disease. ${ }^{7}$

Many epidemiological studies have reported consumption of tobacco to be the major etiology behind oral cancer. ${ }^{8,9} \mathrm{In}$ addition; deaths caused by tobacco hardly make headlines, but tobacco kills one person in every six seconds. ${ }^{10,11}$ Many studies within the South Asian region report the frequent exchange and/or sharing of tobacco products as a way to promote relationship ties and friendship. ${ }^{12,13}$ Furthermore, some studies have suggested that consumption of tobacco in combination with betel quid is also linked with relieving 
stress and / or help keep chewing workers awake because of the presence of pharmacologically active ingredients. ${ }^{12,14}$

Globally, tobacco is available in two major forms: smoked and smokeless. The common smoked form includes cigarettes, cigars, e-cigarettes and hookahs whereas the smokeless is further divided into chewing (betel quid, pan masalas, Gutka), and snuff forms (dry/moist). ${ }^{8}$ Betel quid (BQ) with tobacco and gutka (processed and packaged areca nut with added tobacco and other ingredients) are the most widely used smokeless tobacco (ST) products in the south Asian region (i.e. Pakistan, Bangladesh, India, Sri Lanka, Taiwan etc.) and are the one among four most commonly used psychoactive substances consumed by about six million people around the globe. . $^{8,12,15,16,17}$

Gender wise prevalence of smoking reported by WHO (2013) among Pakistani population was found to be $31.8 \%$ of men, $5.8 \%$ of women, and $19.1 \%$ of adults are currently use tobacco in one form or another. Furthermore, of these overall adult population $17.9 \%$ of men, $1 \%$ of women and $9.6 \%$ of the adults were found to be users of cigarette smoking on daily basis whereas water pipe smokers were $4.4 \%$ of men, $1 \%$ women and $2.7 \%$ were adults. On the other hand, adult's consumption of smokeless tobacco on daily basis was found to be $10.5 \%$ men, $3.5 \%$ women and $7.1 \%$ of adults. However, among young generation $13.3 \%$ of boys, $6.6 \%$ of girls and $10.7 \%$ of all youth were consuming either tobacco in direct form or its derived products. ${ }^{13}$ Moreover, it is also reported by the World Bank that unless urgent action is taken to control the situation, the annual deaths from tobacco will rise more than 8 million by $2030^{18}$ if these trends are not over looked then it will lead to an estimated 500 million people's death associated with tobacco alone. ${ }^{11}$

There is scarcity of data in countries like Pakistan, India, and Bangladesh regarding association of OSMF, its malignant transformation and OSCC with tobacco users in forms i.e chewing \& non chewing (areca nut and betel quid, betel quid and smoking) as well as combination of these habits and their association in causing oral malignancies. Furthermore, there is an utmost need to find out the synergistic effect of combination of chewing and non-chewing habits. These findings could be helpful for further evaluation of rate and progression of OSCC, and will possibly allow high authorities to allocate more resources towards prevention and management of oral cancer.

Therefore, the objective of current study was to evaluate the association among betel nut, betel quid or smoking alone, and betel quid combined with smoking in subjects reporting with oral sub mucous fibrosis, oral sub mucous fibrosis with malignant transformation to oral cancer and oral squamous cell carcinoma.

\section{METHODOLOGY}

A cross sectional, multicentric study of histologically confirmed $n=1009$ cases of OSCC were selected and examined by the principal investigator; from both private and public tertiary care units through a non-probability convenience sampling technique. The age ranges of the subjects were 10 to 70 years of age. Selection criteria was as follow:- all those subjects who had habit of consuming betel nut, tobacco and its derivatives, were agree to be the part of study. However, subjects that were habitual eaters and came to the OPD for other dental procedures, pregnant and lactating females were excluded.

Sample size was determined by WHO sample size calculator. ${ }^{19}$ Clinical details included age, gender, associated habits of eating plain or packaged areca nut alone or with its combinations in the form of betel quid (paan) with or without tobacco, naswar (moist powdered tobacco snuff), smoking tobacco etc.

Data collection was performed by subdividing the total $\mathrm{n}=1009$ subjects into four groups: group 1 , who consumed areca nut only; group 2, who chewed betel quid along with areca nut; group 3, who used betel quid and smoked; and group 4, who had no chewing habits history but were smokers only.

Clinical grading of OSMF was based on the classification proposed by Haider SM and Merchant AT et al. ${ }^{20}$ Clinical oral examinations was performed to detect malignant transformation related to pre-existing OSMF. These transformations were further confirmed with the help of biopsy reports of the subjects with OSMFCa and OSCC. Data were assembled and entered in SPSS version. ${ }^{18}$ Frequencies and percentages were calculated for gender and group wise chewing patterns and chi square test was performed to find out association of chewing habits with the progression of disease state. However, mean and standard deviation was calculated for quantitative. Findings were considered significant with a p-value of less than 0.05.

\section{RESULTS}

Of the total $\mathrm{n}=1009$ subjects, $57.3 \%(\mathrm{n}=578)$ were females and $42.7 \%(n=431)$ were males. The mean age of the sample $(n=1009)$ were $42.79 \pm 1.31$ years (range: $10-70$ years). Moreover, $2.2 \%(n=22)$ of subjects were of ages below 25 years, $54.9 \%(n=554)$ were within 26 to 50 years of age and about $42.1 \%(n=433)$ were aged 51 years and above.

The subjects were divided into four groups according to usage of habits, first group was taking areca nut (AN) only, second group was taking areca nut plus betel quid 
$(\mathrm{AN}+\mathrm{BQ})$, third group was taking betel quid along with smoking (BQ + Smoking), while the fourth group had no chewing habit they were only smokers.

Out of $1009,21.8 \%(n=220)$ were in group 1 who were consuming AN only; $22.7 \%(\mathrm{n}=229)$ in group 2 reported a habit of eating AN plus BQ; group 3: $32.8 \%(n=331)$ reported that they consumed BQ along with a smoking habit; while $22.7 \%(n=229)$ of the subjects in group 4 were smokers only.

Out of total $\mathrm{n}=1009$ subjects, $22.5 \%(\mathrm{n}=$ $227)$ were diagnosed with OSMF alone, $23.2 \%(n=234)$ with OSMFCa while $54.3 \%(n=548)$ were diagnosed with OSCC without pre-existing OSMF.

The descriptive analysis of chewing habits with the type of oral disease is described in table 1 . The relationship of the type of oral habits and type of oral disease is represented in table 2 .

Table 1: Descriptive analysis of oral habits and types of oral disease

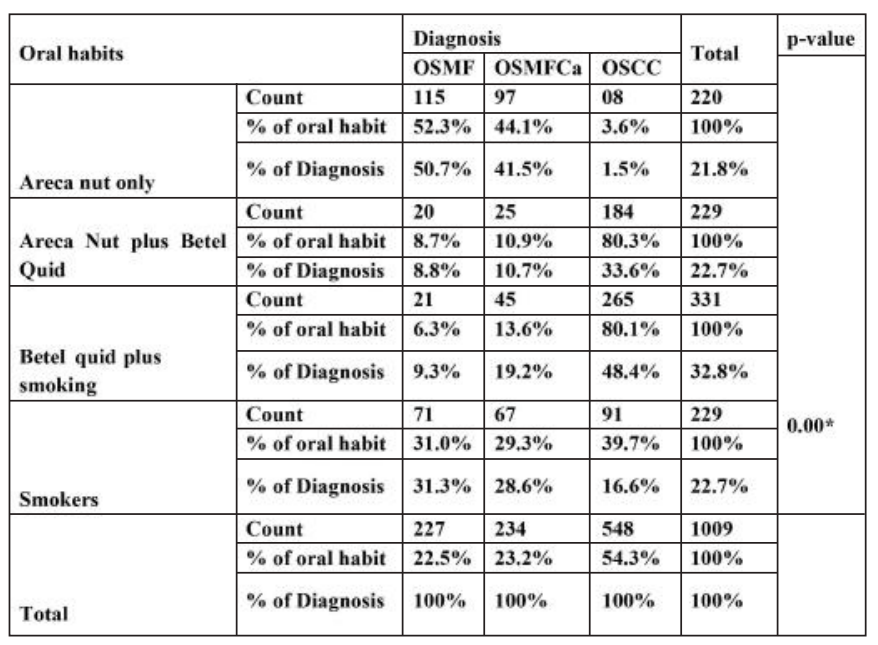

- *Statistically significant

- Chi-square Test

Table 2: Association of oral habits and type of oral disease

\begin{tabular}{|l|l|l|}
\hline \multirow{4}{*}{$\begin{array}{l}\text { With respect to } \\
\text { oral habits }\end{array}$} & p-value \\
\cline { 2 - 3 } & Group 1 vs group 2 & $\mathbf{0 . 0 0}$ \\
\cline { 2 - 3 } & Group 1 vs group 3 & $\mathbf{0 . 0 0}$ \\
\cline { 2 - 3 } & Group 2 vs group 3 & $\mathbf{0 . 4 0 0}$ \\
\hline
\end{tabular}

*Statistically significant

\section{DISCUSSION}

In the current study we have reported the disease trend among chewers (users of areca nut, betel quid and tobacco), non-chewers (i.e smokers only) and also among subjects who had a combination habit of chewing and smoking tobacco. Furthermore, we have found that subjects who were consuming either areca nut alone or habit of tobacco smoking; reported with increased numbers of oral sub mucous fibrosis as well as malignant transformation of oral sub mucous fibrosis. On the other hand, subjects who were consuming betel quid in combination with areca nut and betel quid in combination with smoking; reported with increased numbers of oral squamous cell carcinoma. We had found statistically insignificant association among the subjects who had habit of chewing betel quid along with areca nut and chewing betel quid along with smoking with progression of oral malignant conditions i.e OSMF, OSMFCa and OSCC. Oral carcinogenesis is a progressive, multistage process in which genetic and phenotypic molecular markers are involved in enhancing the function of several proto-oncogenes, oncogenes by deactivating tumor suppressor genes, thus causing over activity of the growth factors and its cell surface receptors, which can lead to increase messenger signaling intra-cellularly and leads to increase release of transcription factors. Thus oncogenes alone are not responsible for causing cancer however, genes having tumor suppressor activities can result in cellular phenotypic changes and these changes are responsible for increased cell proliferation, loss of cellular cohesion, are able to infiltrate in to local tissue so they can spread to distant sites. ${ }^{21}$

In current study we have found that smoking alone is the weakest cause for developing oral cancer as compare to combination of chewing tobacco habits. This finding is similar to the studies reported by Balaram P et al and Znaor A et al from India as well as in some case control studies reported by Bundgaard $\mathrm{T}$ et al and Madani et al. ${ }^{22-25}$ The reason is as chewing tobacco and its product may have a stronger effect than smoking tobacco because of the direct contact of the carcinogenic substances with the oral epithelium.

In this study we have found that chewing tobacco is strongly related to develop oral cancer. This finding is in corroboration with aforementioned studies. ${ }^{22,23}$ The reason was may be the duration of keeping the chewing tobacco and its products with in the oral cavity either with or without lime. Another similar finding was reported by Muwonge et al that smokeless tobacco users were at higher risk of developing oral cancer, along with some other oral abnormalities as compare to smokers alone. ${ }^{26}$

Moreover similar to current studies evidences have suggested that chewing betel quid with tobacco, tobacco consumed by chewing with lime, betel quid with or without tobacco, and areca nuts are human carcinogens. ${ }^{27,28}$ However current study has reported that in addition to the carcinogenicity of these products, combination of chewing tobacco habits are more potent cause of oral cancer among 
Pakistani population.

It has been suggested that both dental and medical health care professionals should work together for initiation of chewing tobacco cessation awareness among high risk groups. There is also a need for designing and implementation of polices; regarding either to reduce availability or increase taxation over all kinds of tobacco products. In addition, mass media campaigns will be needed to spread awareness about the harmful effects of tobacco and its derivatives. Strategies suggested for the control of betel quid may include: elimination of carcinogenic constituents from the products as well as motivating teenagers through public education and law enforcement not to take up these habits while enhancing the intake of antioxidant containing green vegetables and beta-carotene.

\section{CONCLUSION}

Current study concluded that subjects who have combined habits of consuming betel quid with areca nut and/or betel quid with smoking were at highest risk of initiation and progression of oral cancer. However, smoking tobacco only was found the weakest risk factor for developing oral cancer.

\section{CONFLICT OF INTEREST}

None to declare

\section{REFERENCES}

1. World Health Organization. Latest global cancer data: Cancer burden rises to 18.1 million new cases and 9.6 million cancer deaths in 2018 . https://www.who.int/cancer/PRGlobocanFinal.pdf

2. Nagai H, Kim YH. Cancer prevention from the perspective of global cancer burden patterns.J Thorac Dis.2017;9:448-51 https://doi.org/10.21037/jtd.2017.02.75

3. Gupta N, Gupta R, Acharya AK et al.Changing trends in oral cancer-a global scenario.Nepal J Epidemiol.2016;6:613-19. https://doi.org/10.3126/nje.v6i4.17255

4. Bray F, Ferlay J, Soerjomataram I, Siegel RL, Torre LA, Jemal A. Global cancer statistics 2018: GLOBOCAN estimates of incidence and mortality worldwide for 36 cancers in 185 countries. CA Cancer J Clin. 2018; 68:394-424.

https://doi.org/10.3322/caac.21492

5. Wu S, Zhu W, Thompson P, Hannun AY. Evaluating intrinsic and non-intrinsic cancer risk factors.Nat Commun.2018; 9(3490):1-12. https://doi.org/10.1038/s41467-018-05467-z

6. Bornigen D, Ren B, Pickard R, Li J, Ozer E, Hartmann EM et al. Alterations in oral bacterial communities are associated with risk factors for oral and oropharyngeal cancer. Scientific reports. 2017; 7(17686): 1-13. www.nature.com/scientific reports.

https://doi.org/10.1038/s41598-017-17795-z

7. World Health Organization. WHO Global Report: Mortality Attributable to Tobacco, WHOGeneva.2012,

(http://www.who.int/tobacco/publications/surveillance/rep_mortalit y_attributable/en/, accessed 7 March 2018).

8. Niaz K, Maqbool F, Khan F,Bahadar H, Hassan FI.Smokeless tobacco (paan and gutkha) consumption, prevalence, and contribution to oral cancer. Epidemiol Health. 2017; 39:1-11.

https://doi.org/10.4178/epih.e2017009

9. Kumar M, Nanavati R,Modi TG, Dobariya C. Oral cancer: Etiology and risk factors: A review.J Can Res Ther.2016;12:458-63. https://doi.org/10.4103/0973-1482.186696

10. Mahapatra S, Kamath R, Shetty BK,Binu VS. Risk of oral cancer associated with gutka and other tobacco products: A hospital-based case-control study. J Cancer Res Therapeut. 2015;11:199-203 https://doi.org/10.4103/0973-1482.143332

11. World Health Organization. The global tobacco crisis. WHO report on the global tobacco epidemic, 2008. The MPOWER package. Geneva, 2008;14-15.

http://www.whi.int/tobacco/mpower/en/.

12. Gupta B, Newell W.J. Systematic review and Meta-analysis of association of smokeless tobacco and of betel quid without tobacco with incidence of oral cancer in South Asia and Pacific. PLOS One. 2014;9:e113385.

https://doi.org/10.1371/journal.pone.0113385

13. World health organization. Tobacco control in Pakistan, 2015. https://www.who.int/tobacco/about/partners/bloomberg/pak/en/

14. Anand R, Dhingra C, Prasad S, Menon I. Betel nut chewing and its deleterious effects on oral cavity. J Cancer Res Therapeut.2014;10:499-05

15. Bile KM, Shaikh JA, Afridi HUR, Khan Y. Smokeless tobacco use in Pakistan and its association with oropharyngeal cancer. Eastern Mediterranean Health. 2010;16:24-30

https://doi.org/10.26719/2010.16.Supp.24

16. Stanfill SB, Connolly GN, Zhang L, Jia LT, Henningfield JE, et al. Global surveillance of oral tobacco products: total nicotine, unionised nicotine and tobacco-specific N-nitrosamines. Tob Control.2011. 20: 2.

https://doi.org/10.1136/tc.2010.037465

17. Herzog TA, Murphy KL, Little MA, Suguitan GS, Pokhrel P, et al. The betel Quid Dependence Scale: replication and extension in a Guamanian sample. Drug Alcohol Depend. 2014. 138: 154-160.

https://doi.org/10.1016/j.drugalcdep.2014.02.022

18. World Bank. Curbing the epidemic: Government and economics of tobacco control. Geneva: world Bank, 1999.

https://doi.org/10.1596/0-8213-4519-2 
19. WHO sample size calculator. Available from:

URL: http://www.who.int/chp/steps/resources/sampling/en.

20. Haider SM, Merchant AT, Fikree FF, Rahbar MH. Clinical and functional staging of OSMF. Br J Oral MaxillofacSurg. 2000;38: 12-5.

https://doi.org/10.1054/bjom.1999.0062

21. 16. Jain A. Molecular pathogenesis of oral squamous cell carcinoma.In: Squamous cell carcinoma - Hallmark and treatment modalities. IntechOpen; 2019. p. 1-15.

https://doi.org/10.5772/intechopen.85650

22. Balaram P, Sridhar H, Rajkumar T, Vaccarella S, Herrero R, Nandakumar A, et al. Oral cancer in southern India: The influence of smoking, drinking, paan-chewing and oral hygiene. Int J Cancer 2002;98:440-5.

https://doi.org/10.1002/ijc.10200

23. Znaor A, Brennan P, Gajalakshmi V, Mathew A, Shanta V, Varghese $\mathrm{C}$, et al. Independent and combined effects of tobacco smoking, chewing and alcohol drinking on the risk of oral, pharyngeal and esophageal cancers in Indian men. Int J Cancer 2003;105:681-6. https://doi.org/10.1002/ijc.11114
24. Bundgaard T, Wildt J, Frydenberg M, Elbrønd O, Nielsen JE.Casecontrol study of squamous cell cancer of the oral cavity in Denmark. Cancer Causes Control 1995;6:57-67.

https://doi.org/10.1007/BF00051681

25. Madani AH, Dikshit M, Bhaduri D. Risk for oral cancer associated to smoking, smokeless and oral dip products. Indian J Public Health 2012;56:57-60.

https://doi.org/10.4103/0019-557X.96977

26. Muwonge R, Ramadas K, Sankila R, Thara S, Thomas G, Vinoda $\mathrm{J}$, et al. Role of tobacco smoking, chewing and alcohol drinking in the risk of oral cancer in Trivandrum, India: a nested case-control design using incident cancer cases. Oral Oncol 2008;44:446-54.

https://doi.org/10.1016/j.oraloncology.2007.06.002

27. Sudha S, Mythili B, Balachandar V. Mixture of betel leaf, areca nut and tobacco chewing is a risk factor for cytogenetic damage in construction workers from south India. Braz J Oral Sci 2009;8: 145-48.

28. Niaz K, Maqbool F, Khan F, et al. . Smokeless tobacco (paan and gutkha) consumption, prevalence, and contribution to oral cancer. Epidemiol Health. 2017;39:e2017009.

https://doi.org/10.4178/epih.e2017009 